\title{
Specific Exceptions Driving Variation: The Role of Orthography in Modern Hebrew Spirantization
}

\author{
Michal Temkin Martínez and Ivana Müllner \\ Boise State University
}

\section{Introduction}

This paper reports results from a production experiment examining the patterns of variation in the morphophonemic alternations present in spirantization in Modern Hebrew, a phenomenon to which there are many exceptions and diverse levels of variation. Real and nonce verbs were used to elicit variation in a sentence completion task as a follow-up to a perception experiment (Temkin Martínez 2010) which found gradient levels of acceptability in variation due to the presence of exceptionality. The diverse patterns of variation indicate that not all exceptions affect the same level of variation in alternation. Results of the current study suggest that levels of gradience are linked to the presence or absence of multiple orthographic representations for each of the segments involved. An Optimality Theoretic (OT) account modifying a combined model of set-indexation (Pater 2000) and Stochastic OT (Boersma 1998; Boersma \& Hayes 2001; Hayes \& Londe 2006; Hayes \& MacEachern 1998; Zuraw 2000) presented in Temkin Martínez (2010) is provided to account for the alternation patterns in nonce verbs.

1.1 Modern Hebrew Spirantization Spirantization is a phenomenon that can be traced backto older forms of Hebrew, such as Tiberian Hebrew (TH). In Modern Hebrew (MH), this phenomenon is characterized by the alternation of the stops $[\mathrm{p}]$, [b], and $[\mathrm{k}]$ with their fricative counterparts [f], [v], and $[\chi]$. As seen in the spirantization distribution in (1), fricatives generally occur in post-vocalic position and stops occur elsewhere.

Spirantization distribution in $\mathrm{MH}$

$\begin{array}{lllll} & \text { Root }^{1} & \text { Infinitive } & 3^{\text {rd }} \text { Person Sg.Past.m. } & \text { Gloss } \\ {[\mathbf{p}] \sim[\mathbf{f}]} & / \mathbf{p g} \int / & {[\text { lifgof] }} & {[\text { paga }]} & \text { 'to meet' } \\ {[\mathbf{b}] \sim[\mathbf{v}]} & / \mathbf{b g d} / & {[\text { livgod }]} & {[\text { bagad }]} & \text { 'to betray' } \\ {[\mathbf{k}] \sim[\chi]} & / \mathbf{k t b} / & {[\text { liztov }]} & {[\text { katav }]} & \text { 'to write' }\end{array}$

In $\mathrm{MH}$, there are some exceptions to spirantization. These exceptions include non-alternating [p], [b], [k], $[\mathrm{f}],[\mathrm{v}]$, and $[\chi]$, which can result in stops occurring in post-vocalic position or in fricatives elsewhere. These non-alternating segments did not participate in the spirantization distribution in older forms of Hebrew due to their status as underlying spirants, emphatic stops, or geminates which did not undergo spirantization. Borrowings may also exhibit exceptional, non-alternating segments. In $\mathrm{MH}$, to historical sound changes, these exceptional segments are acoustically identical to their alternating counterparts. In some cases, however, the distinction between alternating and non-alternating segments is encoded orthographically in MH. Specifically, exceptional $/ \mathrm{k} /(<* \mathrm{q}), / \chi /(<* \hbar)$, and $/ \mathrm{v} /\left(<*_{\mathrm{w}}\right)$ are represented by a

\footnotetext{
* The authors wish to thank the audience at the 2015 Annual Meeting on Phonology, and to Revital Zilonka for her help with stimuli for the experiment. The study was supported by the Boise State University College of Arts and Sciences and the English Department.

${ }^{1}$ No claim is being made here as to whether the UR of spirantized segments is a stop or fricative. (C) 2016 Michal Temkin Martínez and Ivana Müllner

Proceedings of AMP 2015

Completed April 10, 2016
} 
different grapheme from alternating $/ \mathrm{k} /([\mathrm{k}] \sim[\chi])$ and $/ \mathrm{b} /([\mathrm{b}] \sim[\mathrm{v}])$. Conversely, all $[\mathrm{p}]$ and $[\mathrm{f}]$ sounds are represented with one grapheme regardless of their alternation or exceptionality. Examples of these phonological exceptions appear in (2). A full description of the orthographic representations of the sounds can be found later in (4).

Examples of exceptions to spirantization in $\mathrm{MH}$

\begin{tabular}{|c|c|c|c|c|}
\hline & $\underline{\text { Root }}$ & Infinitive & $3^{\text {rd }}$ Person Sg.Past.M. & Gloss \\
\hline & $/ \mathbf{v t r} /$ & [levater] & [viter] $(*$ biter $)$ & 'to give up' \\
\hline$/ \mathbf{k} /(<* \mathrm{q})$ & $/ \mathbf{k r} ? /$ & [likro] (*li $\chi \mathrm{ro})$ & [kara] & 'to read' \\
\hline
\end{tabular}

Variation in alternating segments has also been reported in the literature (Schwartzwald 1981, Adam 2002, Temkin Martínez 2010). This variation is characterized by segments that normally do conform to the spirantization distribution in (1) surfacing as stops where fricatives are expected or as fricatives where stops are expected, as illustrated by the bolded segments in the acceptable variants in (3).

Variation in MH spirantization

$\begin{array}{lllll} & \text { Root } & \text { Expected } & \text { Acceptable Variant } & \text { Gloss } \\ / \mathbf{b} / & / \mathrm{kbr} / & {[\text { likbor] }} & {[\text { likvor] }} & \text { 'to bury' } \\ / \mathbf{k} / & / \mathbf{k s h} / & \text { [jexase] } & \text { [jekase] } & \text { 'will cover' }\end{array}$

Adam (2002) claims that this variation is due to the presence of non-alternation (or exceptions) in the language, characterizing it as free variation resulting from a "conflict [which] entails a competition between two grammars: one which allows alternation and one which blocks it." In Temkin Martínez (2010), an acceptability-rating task illustrated that variation is indeed acceptable in alternating segments, but the expected allophone had a much higher rate of acceptability than the acceptable variant. Additional preference patterns illustrated that variation was deemed more acceptable in post-consonantal position than in word-initial or post-vocalic positions, and that there was no overall preference for stops or fricatives.

Since some of the exceptionality in MH is driven by sound mergers from older forms of the language, non-alternation is sometimes encoded in the orthography. Namely, the merged non-alternating segments [v] $(<* \mathrm{w})$ and $[\chi](<* \hbar)$ and $[\mathrm{k}]\left(<*^{*} \mathrm{q}\right)$ are represented with a different grapheme than are alternating $/ \mathrm{k} /$ and $/ \mathrm{b} /$, while the degeminated non-alternating stops $[\mathrm{k}]$, $[\mathrm{p}]$, and $[\mathrm{b}]$ are not. ${ }^{2}$ Consequently, the voiceless labials are represented by only one grapheme, regardless of whether they alternate or are exceptional, whereas the voiced labial fricative is represented differently from its exceptional stop and alternating counterparts, and the dorsals are represented with three graphemes - one for the alternating segment, and two distinct graphemes for the exceptional segments. This is illustrated in (4). Note that the descriptions of non-alternating segments that have different orthographic representations than their alternating counterparts are followed by an asterisk.

Written representations for segments

\begin{tabular}{|c|c|c|c|}
\hline & Alternating & Exceptional Stop & Exceptional Fricative \\
\hline$[\mathrm{p}] /[\mathrm{f}]$ & 9 & $\begin{array}{l}\text { - geminate and non-alt. } \\
\text { paradigms }\end{array}$ & $\begin{array}{l}\text { [f] in borrowings, less frequent } \\
\text { than other exceptional fricatives }\end{array}$ \\
\hline$[\mathrm{b}] /[\mathrm{v}]$ & ב & $\begin{array}{l}\text { ב - geminate and non-alt. } \\
\text { paradigms }\end{array}$ & $\begin{array}{l}\text { from TH [v], also in borrowings } \\
(\text { i.e. } / \mathrm{vtr} / \text { in }(2))^{*}\end{array}$ \\
\hline$[\mathrm{k}] /[\chi]$ & כ & $\begin{array}{l}P \text { from TH }[\mathrm{q}](\mathrm{i} . \mathrm{e} . / \mathrm{kr} ? /(2))^{*} \\
\supset \text { - geminate and non-alt. } \\
\text { paradigms }\end{array}$ & $\begin{array}{l}\pi \text { from } \mathrm{TH}[\hbar] \text {, also in } \\
\text { borrowings* }\end{array}$ \\
\hline
\end{tabular}

\footnotetext{
${ }^{2}$ In cases of ambiguity, these are sometimes represented orthographically with a small diacritic inside the grapheme but
} not with a different grapheme. 
The experiment in the present study utilizes these orthographic distinctions in order to identify speakers' underlying representation of a certain segment in nonce words. In addition to verifying the production of real verbs, this experiment also examines alternation patterns and spelling choices of nonce verbs to determine variation in production patterns.

1.2 Aims and hypotheses of the present study The experiment described here looks at speakers' production patterns, especially when presented with novel verbs. Namely, we examine whether production patterns of real verbs match those found in the perception experiment in Temkin Martinez (2010), and whether patterns of variation in segments in nonce verbs are uniform or gradient.

In real verbs, we hypothesize that patterns of variation in alternation of the segment will match those found in Temkin Martínez (2010). Specifically, (A) variation in alternating forms should be greater than in exceptional forms, and (B) variation should be higher in post-consonantal position than word-initially and post-vocalically.

In nonce words, we examined patterns of alternation in participants' production and whether the alternation patterns matched their selection of an orthographic representation for the root. Following the patterns of real verbs, we assumed that variation would be more acceptable in alternating segments than in non-alternating segments. We therefore hypothesized that (A) when participants opted to alternate, they would prefer to represent the segment with the grapheme associated with alternation. Additionally, we hypothesized that (B) nonce words produced with non-alternation would be written as either containing the grapheme representing the alternating segment or the one representing the exceptional segment corresponding to the sound produced. Because of the fact that the dorsals can be represented by three different graphemes - one for the alternating segment, one for the non-alternating stop, and one for the nonalternating fricative - we hypothesized that $(\mathrm{C})$ upon hearing $[\mathrm{k}]$ or $[\chi]$, participants would be least likely to produce an alternating segment. Finally, following Temkin Martínez (2010), we hypothesized that (D) segments in nonce verbs would be least likely to alternate when they were produced in post-consonantal position.

\section{Methodology}

Data for the current production study was collected in a sentence-completion task in Israel over a tenday period, mainly in the Tel Aviv area. Participants were presented with recorded sentences containing a verb inflected for one tense and had to complete a second sentence using the same verb with a different inflection. The different inflections resulted in a different word position for the target segment in question, allowing for the choice to alternate. For sentences in which the target verb was a nonce word, in addition to performing the sentence-completion task, participants were asked to write down their perceived spelling of the nonce root. This allowed for the comparison of participants' choice of alternation or non-alternation in the production of the nonce verb with their choice of its orthographic representation.

2.1 Stimuli Stimuli for the experiment contained words formed from 44 real and 32 nonce verb roots. These roots contained the segments in question ([p], [b], [k], [f], [v], and $[\chi])$ in either root-initial or rootmedial position, and each root was inflected for two tenses, requiring the segment to appear in two distinct word positions. Segments in root-initial position appeared in word-initial and post-vocalic positions, while those in root-medial position appeared in post-vocalic or post-consonantal positions. Using two morphological templates, ${ }^{3}$ eight filler nonce roots containing only sounds not affected by spirantization ([d], [r], [1], etc.) were also inflected and included, for a total of 168 tokens (88 reals, 64 nonce, and 16 fillers).

In order to compare the perception and production patters of the real verbs, tokens in the production study were identical to those used in the 2010 study. Tokens were divided into two lists, each containing

\footnotetext{
${ }^{3}$ In Hebrew verb morphology, triconsonantal roots may be plugged into one of seven available morphological templates, or binyanim. Each inflection and template requires the addition of different vowels and affixes to form a lexical item. The two morphological templates in the filler nonce roots matched the templates of the other tokens in the experiment (PA'AL and PI'EL).
} 
two of the four target forms of the nonce verbs. Most nonce verbs were presented twice per list, with one inflection in Template 1 (PI'EL) and another in Template 2 (PA'AL). This allowed for two tokens per root per participant. The target inflections of these two tokens had the same tense (either past or infinitive) so as not to prime participants with a previously heard pronunciation of the inflected root. The other list contained the same nonce verb with the opposite target inflection. Each list contained a total of 84 randomized tokens. Nonce tokens containing the target segment in root-medial position were only inflected in Template 2. This is because such root-medial segments were historically geminated in Template 1 , deeming them non-alternating segments in $\mathrm{MH}$.

Nonce verbs in the sentences heard by participants were inflected according to the spirantization distribution in (1) - with word-initial and post-consonantal stops and post-vocalic fricative - making it impossible for participants to know whether the segment was alternating or exceptional. Sample inflections for nonce roots are given in (5).

Sample inflections for nonce roots

\begin{tabular}{|c|c|c|c|c|c|}
\hline \multirow{2}{*}{$\begin{array}{l}\text { Segment } \\
\text { Pair }\end{array}$} & \multirow[t]{2}{*}{ Root } & \multicolumn{2}{|c|}{ Template 1 (PI'EL) } & \multicolumn{2}{|c|}{ Template 2 (PA'AL) } \\
\hline & & Past & Infinitive & Past & Infinitive \\
\hline $\mathrm{k} / \chi$ & $/ \mathrm{krl} /$ & [kirel] & [lexarel] & [karal] & [lizrol] \\
\hline $\mathrm{b} / \mathrm{v}$ & $/ \mathrm{bgl} /$ & [bigel] & [levagel] & [bagal] & [livgol] \\
\hline
\end{tabular}

In preparation for the sentence-completion task, target words (both real and nonce) were inserted into carrier sentence pairs. Each pair contained a verb in the first sentence, but lacked the verb at the end of the second sentence. Crucially, the tenses in the two sentences in each pair were arranged such that the target segment's position would be different in the first and second sentences. Therefore, participants' realizations of each target segment would indicate whether they perceived it as alternating or exceptional. A sample sentence pair appears in (6). Participants were asked to listen to the first sentence and then complete the second one with the correct form of the verb.

(6) Sample target sentence

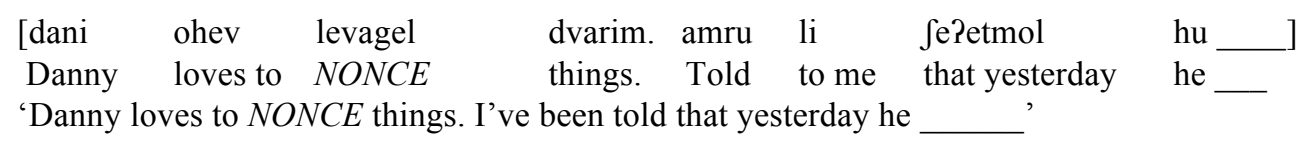

2.2 Participants Forty-eight native speakers of $\mathrm{MH}$ residing in Israel participated in the study. Only participants who indicated (on a demographic survey completed after the task) that Hebrew was both their first and home language were included in the analysis. ${ }^{4}$ Twenty-nine female participants and 19 male participants, ranging in age from 22 to 46, were included in the study. All had at least a high school education, and some had advanced degrees.

2.3 Procedure Participants were aurally presented with one sentence pair at a time. They were asked to complete the second sentence of each pair with the appropriate inflection of the verb provided in the first sentence. In sentences containing nonce verbs, participants were also asked to write down the perceived orthographic representation of the verb root, thus revealing whether their production of alternation or nonalternation matched the expected allophone of the underlying representation, provided in their writing. Participants were able to repeat sentences multiple times, and their oral responses were recorded using a Shure lapel microphone with a Zoom $\mathrm{H} 4 \mathrm{n}$ audio recorder.

Audio files were coded by the two authors for inter-rater reliability. When participants offered two different oral responses to a single sentence pair, only the second response was used.

\footnotetext{
${ }^{4}$ Of the 50 participants recruited, two had marked a language other than Hebrew as their first or home language. Those participants' responses were not included in the analysis.
} 


\section{Results}

3.1 Real verbs Our hypothesis for real verbs states that production patterns will match those in the perception experiment in Temkin Martínez (2010). This entails the following two claims: (A) variation in alternating segments should be higher than in exceptional segments, and (B) variation should be higher in post-consonantal position than in word-initial or post-vocalic position.

As seen in (7), variation in the production of alternating segments in real verbs was indeed higher than that of exceptional segments. In fact, a repeated measures ANOVA revealed a main effect of segment type $(\mathrm{F}(1,48)=934.552, p<.001)$ as well as a main effect of whether the allophone produced was the expected or variant allophone $(\mathrm{F}(1,48)=1991.804, p<.001)$ and a significant interaction between the two factors $(\mathrm{F}(1,48)=571.322, p<.001)$.

(7) Real verbs: variation in alternating vs. non-alternating segments

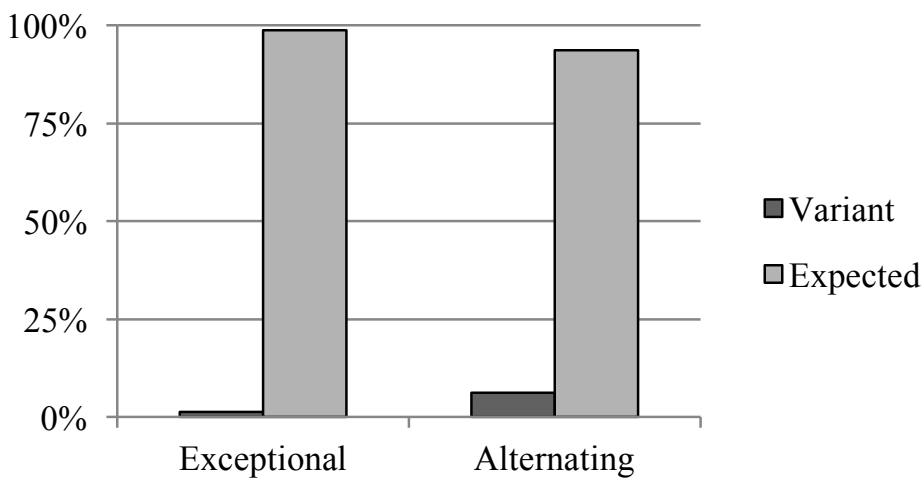

Following Temkin Martínez (2010), we also predicted higher levels of variation in post-consonantal position. In (8) and (9), we see that variation for the alternating segment in post-consonantal position drives significant difference between alternating and exceptional segments. For the alternating segments, a repeated measures ANOVA reveals a main effects of word position $(\mathrm{F}(1,48)=722.647, p<.001)$ and of whether the allophone produced was the expected or variant one $(\mathrm{F}(1,48)=1965.876, p<.001)$ as well as a significant interaction between the two $(\mathrm{F}(1,48)=63.489, p<.001)$.

(8) Real Verbs: variation in alternating segments by word position

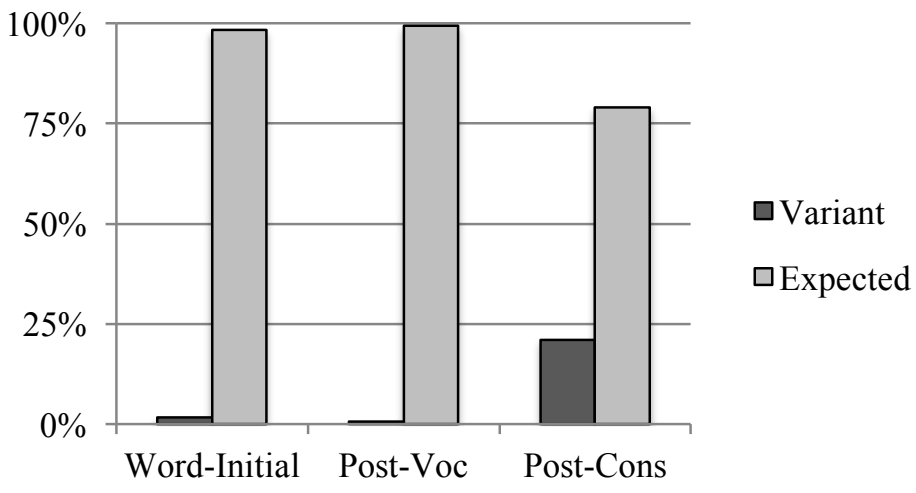

Unlike alternating segments, exceptional segments did not exhibit the same variation patterns across word positions. Rather, despite low levels of variation overall, higher variation in word-initial position seems to drive the main effects of word position for exceptional segments $(F(1,48)=311.661, p<.001)$ and expected or variant allophone $(\mathrm{F}(1,48)=1948.776, \mathrm{p}<.001)$ as well as their significant interaction $(\mathrm{F}(1,48)=257.964, \mathrm{p}<.001)$. This is seen in $(9)$. 
Real verbs: variation in non-alternating segments by position

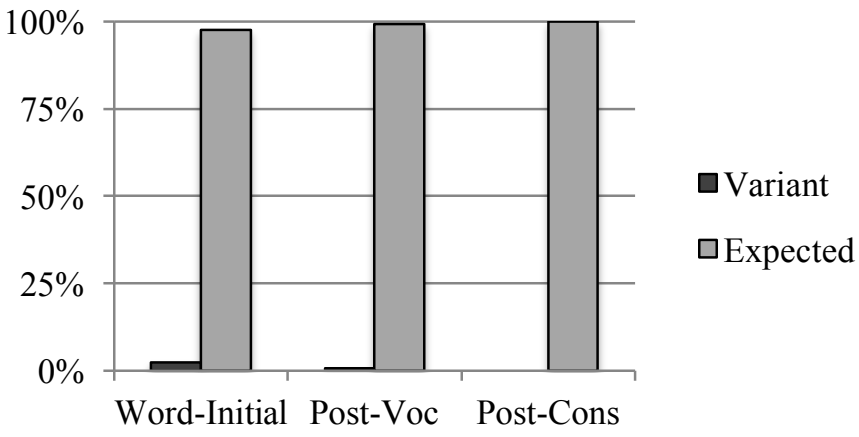

3.2 Nonce verbs Recall that, in addition to the production of real verbs, participants were asked to produce nonce verbs in order to determine whether the pattern of variation of alternation transcended lexical items. In addition to production data, we also collected data on the participants' choices in orthographic representation of nonce verbs in order to analyze whether their production matched the behavior of the underlying segment they were considering. Therefore, variation would be represented by a mismatch between a participant's choice to alternate or not alternate and the orthographic representation (i.e. not alternating the segment in production but writing down the grapheme that corresponds with alternation).

One of the major claims of this study is that variation in alternation and exceptionality is influenced by the spelling of the word. In our hypothesis, we predicted that nonce words produced with alternation would be written exclusively as alternating segments (i.e. using the orthographic symbol associated with alternation) while nonce words that were produced with non-alternation would be written as either alternating or exceptional segments. Words produced with non-alternation and written as alternating (i.e. the spelling did not match pronunciation) were analyzed as evidence of variation since the speaker underlyingly perceived the segment as alternating but produced it without alternating.

In (10), we see a significant correlation between the production of an alternating segment and orthographic representation used by the participants $(\mathrm{F}(1,48)=1462.273, p<.001)$. That is, when participants produced alternating segments, they overwhelmingly preferred using the grapheme associated with alternation. However, a different trend was observed in the production of non-alternating segments. While participants usually opted to use the grapheme associated with non-alternation, they also selected the grapheme associated with alternation in some cases. While there was no main effect of whether participants chose to alternate the segment $(\mathrm{F}(1,48)=.045, p=.705)$, there was a significant interaction between the choice to alternate and whether the spelling matched the alternation choice $(\mathrm{F}(1,48)=10.569, p=.002)$.

(10) Nonce verbs: matching orthography to alternating vs. non-alternating production

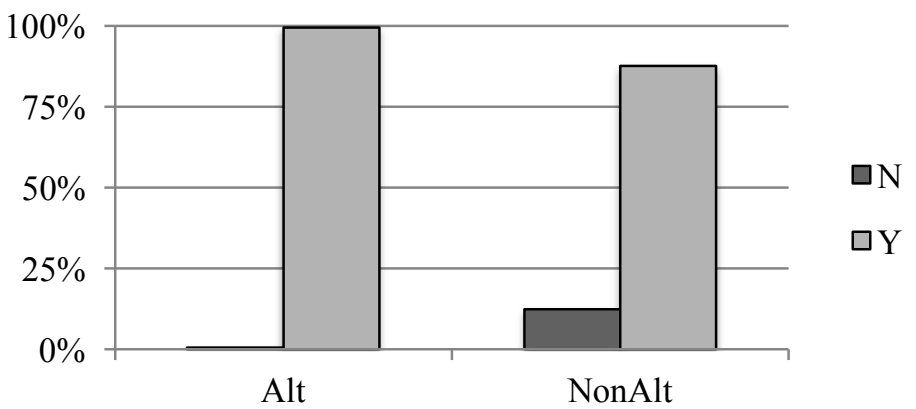

Recall that we also sought to compare how different segments behaved in nonce verbs, focusing specifically on the segments that had multiple orthographic representations for the alternating and exceptional forms. Based on these orthographic patterns, we expected the highest preference for nonalternation in dorsals, and highest preferences for alternation in the voiceless labials. In (11), we see that upon hearing a dorsal (either the stop or fricative), participants opted to not alternate the segment. 
Additionally, while there was still a preference for alternation upon hearing the voiced labial fricative (for which there is a non-alternating grapheme), the level of non-alternation produced by participants was significantly higher than the ones corresponding to the voiceless labials and the voiced labial stop for which there are no non-alternating graphemes $(\mathrm{F}(1,44)=20.448, p<.001)$. Two post-hoc Tukey tests showed a significant difference in the means of $[\mathrm{k}]$ and $[\chi]$ and those of $[\mathrm{p}],[\mathrm{f}],[\mathrm{b}]$ and $[\mathrm{v}]$ in both alternating and non-alternating allophones in nonce verbs.

Nonce verbs: alternation across segments

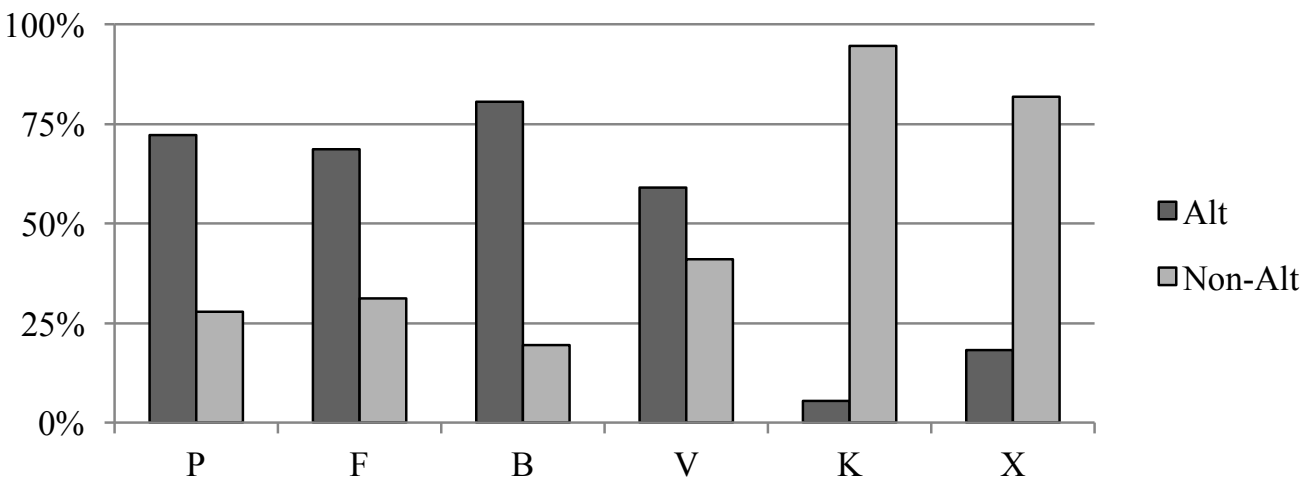

This can be further explained by looking at the production of stops and fricatives in each position in each of the stop/fricative pairs. Looking at patterns of alternation based on the segment heard in the first sentence, in (12) we see that $/ \mathrm{b} /$ and $/ \mathrm{v} /$ pattern similarly to $/ \mathrm{p} /$ and $/ \mathrm{f} /$, following the spirantization distribution with a preference for word-initial stops, post-vocalic fricatives, and post-consonantal fricatives. However, the dorsals $/ \mathrm{k} /$ and $/ \chi /$ pattern differently, exhibiting word-initial fricatives and post-vocalic stops demonstrating a preference for non-alternation as predicted.

(12) Nonce verbs: fricative/stop distribution across positions and segments

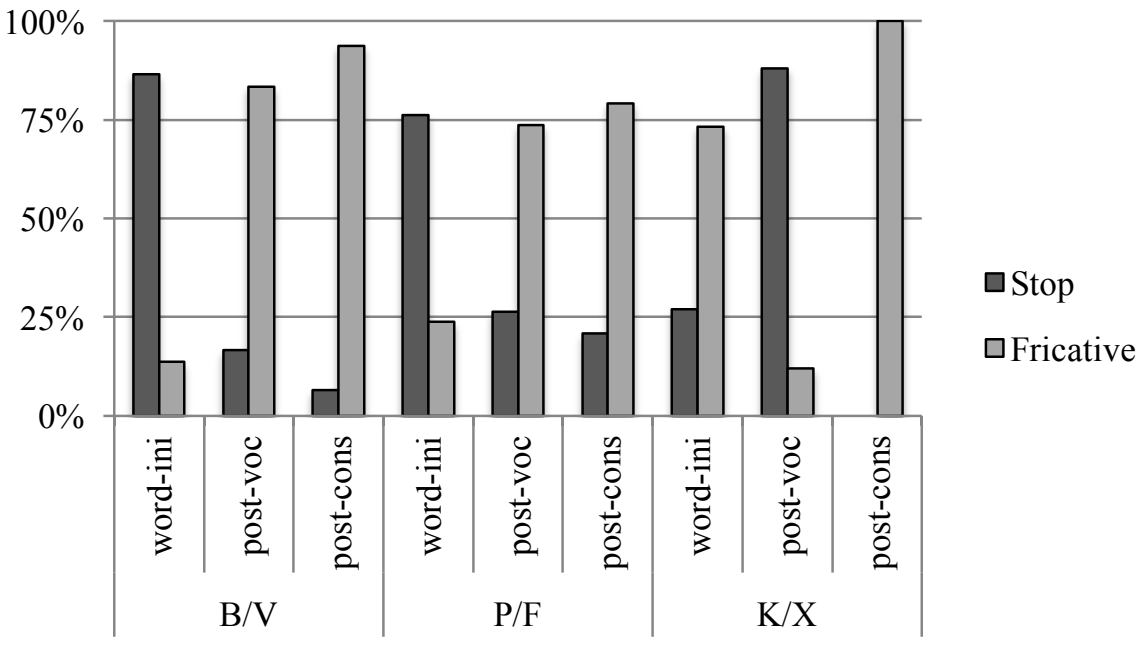

Finally, examining word position effects, our hypothesis stated that preference for variation in nonce verbs should match the patterns seen in real verbs. Results in (13) show that alternation is preferred in wordinitial position and in post-vocalic position, but not in post-consonantal position. A repeated measures ANOVA reveals a main effect of position $(\mathrm{F}(1,48)=961.031, p<.001)$ and a significant interaction between word-position and alternation $(\mathrm{F}(1,48)=32.095, p<.001)$. 
Nonce verbs: alternation by word position

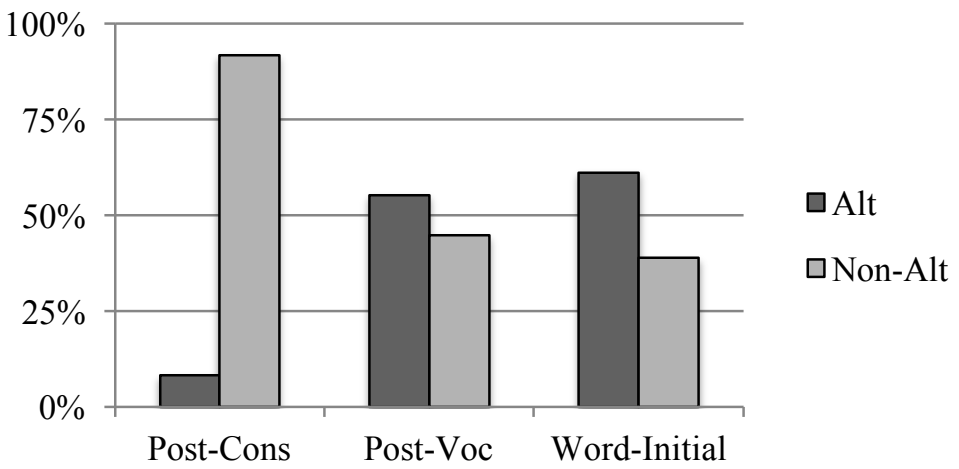

\section{Analysis}

Summarizing the findings of the present study, we see that variation in real verbs is higher in alternating segments than in non-alternating segments. Additionally, real verbs containing alternating segments match the predicted word-position patterns found in Temkin Martinez (2010) with a higher rate of variation in post-consonantal position where a stop is expected but the production of a fricative is preferred. The effect of word-position is also seen in nonce verbs where non-alternation is preferred in post-consonantal position. Finally, we see that, in the nonce verbs, non-alternation is preferred among the dorsals, which correspond with three distinct graphemes. On the other hand, alternation is preferred among the labials, with the highest level of acceptable non-alternation being found in the voiced fricative (for which there is a corresponding non-alternating grapheme). The following analysis allows us to account for the patterns in real verbs found in Temkin Martínez (2010) and confirmed here, as well as for the patterns of alternation found in the nonce verbs in the present study.

4.1 Real Verbs Non-alternating segments, or exceptions to Modern Hebrew spirantization, seem to be driving high rates of acceptable non-alternation in segments that normally alternate in the spirantization distribution (Adam 2002). The production experiment described here confirms the perception results from Temkin Martinez (2010). Since both the perception and the production studies show gradience in the levels of variation, the analysis must reflect the lack of free variation. Temkin Martinez (2010) proposes an Optimality Theoretic (OT) analysis that combines Stochastic OT (Boersma 1998; Boersma \& Hayes 2001; Hayes \& Londe 2006; Hayes \& MacEachern 1998; Zuraw 2000) with set indexation (Pater 2000) to allow for both gradience and exceptionality, respectively.

In Stochastic OT, the Gradual Learning Algorithm (GLA) calculates the probability of different constraint rankings and assigns ranking values to the constraints involved based on the frequency of the candidates for each input. To calculate these frequencies based on results from the experiment, all possible candidates for a given token were included along with their frequency (presented as a percentage of the total number of productions for a given input). The GLA cycles through the grammar (input/output pairs, candidate frequencies, and constraint violations) and assigns constraint values, determining their ranking. The stochastic grammar then attempts to match the candidate frequencies from the input. For example, in (14), the candidates for the real verb [bitel] [vitel] occurred in the experiment 77 and 23 percent of the time and were generated nearly 75 and 25 percent of the time in the GLA-generated grammar, respectively. All stochastic rankings were calculated using OTSoft (Hayes et al. 2013).

Rankings for [bitel] (expected, 77.1\%) [vitel] (variant, 22.9\%) 'he cancelled'

[bitel] $=*[+$ cont, - sib] $\rrbracket *$ Stop (occurs $74.7 \%$ in grammar):

\begin{tabular}{|c||l|l|l|l|}
\hline $\begin{array}{c}\text { /btl } /+3 p \text {.sg.m.past } \\
\text { 'he cancelled' }\end{array}$ & $* V$-STOP & $*[+$ cont, - sib] & IDENT-IO[cont] & $*$ STOP \\
\hline \hline a. bitel & & & & $*$ \\
\hline b. vitel & & $* !$ & $*$ & \\
\hline
\end{tabular}




[vitel] $=*$ Stop $\gg *[+$ cont, -sib] (occurs $25.3 \%$ in grammar):
\begin{tabular}{|c||l|l|l|l|}
\hline $\begin{array}{c}\text { /btl/ + 3p.sg.m.past } \\
\text { he cancelled }\end{array}$ & $*$ V-STOP & $*$ STOP & $*$ [+cont, -sib] & IDENT-IO[cont] \\
\hline \hline a. bitel & & $* !$ & & \\
\hline b. vitel & & & $*$ & $*$ \\
\hline
\end{tabular}

Using only stochastic constraint ranking, we are unable to account for the distinction in acceptable variation between alternating and exceptional segments since the GLA treats both equally. Results from both experiments indicate that variation is significantly less acceptable in exceptional segments. With no set-indexed constraints, the GLA averages the rate of acceptability across all segments, increasing the discrepancy between input and generated frequencies. This is especially problematic in cases like the one illustrated in (15), where the roots $/ \mathrm{kfP} /$ and $/ \mathrm{kfh} /$ are acoustically identical but behave quite differently in relation to alternation because $/ \mathrm{kf} /$ contains a non-alternating $/ \mathrm{k} /$ and $/ \mathrm{kfh} /$ contains an alternating $/ \mathrm{k} /$. Despite their different behavior and the difference in their input frequencies, candidates for both roots are assigned the same frequency in the generated grammar. As a result, the generated frequency, having to account for both alternating and non-alternating segments simultaneously, is unable to match the input frequencies of either segment type.

/kf?/ 'to freeze' (with non-alternating $/ \mathrm{k} /$ ) and $/ \mathrm{kfh} /$ 'to force' (with alternating $/ \mathrm{k} /$ )

\begin{tabular}{|c|c|c|c|c|}
\hline $\begin{array}{l}\text { Target } \\
\text { (non-alternating } / \mathrm{k} / \text { ) }\end{array}$ & $\begin{array}{l}\text { Input } \\
\text { Frequency }\end{array}$ & $\begin{array}{l}\text { Target } \\
\text { (alternating } / \mathrm{k} / \text { ) }\end{array}$ & $\begin{array}{l}\text { Input } \\
\text { Frequency }\end{array}$ & $\begin{array}{l}\text { Generated } \\
\text { Frequency }\end{array}$ \\
\hline [likfo] & 0.452 & [likfot] & 0.194 & 0.000 \\
\hline [likpo] & 0.435 & [likpot] & 0.104 & 0.339 \\
\hline [lixfo] & 0.048 & [lixfot] & 0.194 & 0.257 \\
\hline [li $\chi$ po] & 0.065 & [lixpot] & 0.507 & 0.404 \\
\hline
\end{tabular}

The combination of set-indexation and Stochastic OT assists in narrowing the gap seen in (15). Setindexation (Pater 2000), an approach used for exceptions, allows for the formation of a set containing only the exceptional elements, along with a cloned constraint that is indexed for the set. The different ranking of the general constraint and the cloned set-indexed constraint allow for differences in alternation. In the case of real verbs in $\mathrm{MH}$, where exceptions rarely alternate, the set-indexed constraint is generally ranked above the relevant markedness constraints. The ranking schema for the combined model is shown in (16). The combined model ranks the probability of the relevant markedness constraints $(* \mathrm{~V}-\mathrm{STOP}, *[+$ cont, $-\mathrm{sib}]$, and *STOP) and of two separate faithfulness constraints for the feature [continuant] - one general, the other an indexed clone that applies only to exceptional, non-alternating segments. The values following each constraint on the bottom line represent the frequency with which the constraint outranks the next constraint.

Schema for exceptionality and alternation using the combined model

IDENT-IO[cont $]_{1}$
Stochastically ranked to allow different frequencies of variants
IDENT-IO[cont $]_{1}(.723) »$ *V-STOP $(.637) »[+$ cont, - sib $](.592) » *$ *STOP $(1) »$ IDENT-IO[cont]

The resulting combined model allows for higher levels of non-alternation in exceptional segments, avoiding violations of the set-indexed faithfulness constraint. At the same time, the model's stochastic rankings of markedness constraints accommodate the higher levels of alternation found in alternating segments, while also allowing for gradient variation. Thus, the combined model allows for both gradience and exceptionality. A tableau illustrating the integration of the combined model as it applies to a real verb is in (17). Note that candidate (a), with a post-vocalic [f] is selected by the algorithm 90 percent of the time, and candidate (b), with a post-vocalic [p] is selected only ten percent of the time. Candidates (c) and (d), containing a word-initial fricative that corresponds to a non-alternating stop in the input, never surface due to their fatal violations of the set-indexed constraint. 
Tableau for combined model

[kafa] (expected, 90\%) [kapa] (variant, 10\%) 'he froze' ( $\mathrm{k}$ is non-alternating)

\begin{tabular}{|l||l|l|l|l|l|}
\hline $\begin{array}{c}\text { / } \mathrm{k}_{1} \mathrm{ph} /+3 \mathrm{p} . \mathrm{sg} . \mathrm{m} . \mathrm{past} \\
\text { 'he froze' }\end{array}$ & $\begin{array}{l}\text { IDENT-IO } \\
{[\text { cont }]_{1}}\end{array}$ & $*$ V-STOP & $*[+$ cont, -sib] & $*$ STOP & $\begin{array}{l}\text { IDENT-IO } \\
{[\text { cont }]}\end{array}$ \\
\hline \hline b. $\mathrm{k}_{1}$ apa $(0.9)$ & & & $*$ & $*$ & $*$ \\
\hline c. $\chi_{1}$ afa & & $*$ & & $* *$ & \\
\hline d. $\chi_{1}$ apa & $* !$ & & $* *$ & & $* *$ \\
\hline
\end{tabular}

4.2 Nonce Verbs Recall that the nonce verbs were included in the experiment to determine whether there were different preferences for alternation among segments independent of lexical items. Results indicated that upon hearing the dorsals $[\mathrm{k}]$ and $[\chi]$, participants were significantly less likely to alternate the production of the segment. Additionally, participants produced higher rates of non-alternation upon hearing [v] than upon hearing [b], [p], or [f] - the segments for which there are no distinguishable graphemes for alternation versus non-alternation. These preferences can be accounted for in OT by modifying the combined model described in 4.1. This adjustment involves making available two distinct indexed sets one for the dorsals, and another for the voiced labial fricative - with corresponding cloned faithfulness constraints for each set. This allows the two indexed subgroups to interact with the contextual markedness constraints at different levels. The constraint rankings for the nonce verbs are provided with their respective frequencies in $(18)^{5}$

(18) Constraint rankings for nonce verbs using the modified combined model with two indexed sets

$$
\text { IDENT-IO }[\text { cont }]_{\mathrm{k \chi}}(.721) » *\left[\text { FRIC }(.732) » \operatorname{IDENT}-\mathrm{IO}[\text { cont }]_{\mathrm{v}}(1) » * \mathrm{~V}-\mathrm{STOP}(.804) » \operatorname{IDENT}-\mathrm{IO}[\text { cont }]\right.
$$

Indexation for the two sets (marked above with their corresponding segments as subscripts) is based on the notion of orthographic representation of a given stop/fricative pair. The dorsals, which can be represented by three distinct graphemes, are members of a set whose indexed faithfulness constraint is ranked higher than any markedness constraint at least 72.1 percent of the time. This allows for higher rates of nonalternation in verbs containing these segments. The voiced labial fricative, whose stop counterpart does not have its own grapheme but whose level of non-alternation is higher than those of the other labials, is member of the set whose indexed faithfulness constraint varies in its ranking with the constraint prohibiting word-initial fricatives. The preference to alternate in the remaining labials (for which there is only one grapheme) is driven by the interaction of the two contextual markedness constraints and the un-indexed faithfulness constraint. The differences in frequency of alternation accounted for by using the modified combined model are illustrated in the tableaux below. The tableau in (19), containing a [b] in the input, accounts for high rates of alternation in the segments that do not have multiple graphemes. This is enabled by the interaction of the markedness constraint driving spirantization in post-vocalic position and the unindexed faithfulness constraint.

$$
\text { [b] in input: Preference for alternation }[1 \mathrm{l} v \mathrm{vats} \varepsilon \mathrm{m}] /[\text { livtsom }](80 \%) \sim[1 \mathrm{bbats} \varepsilon \mathrm{m}] /[\text { libtsom }](20 \%)
$$

\begin{tabular}{|c|c|c|c|c|c|}
\hline /bitsem/ & $\begin{array}{l}\text { IDENT-IO } \\
{[\text { cont }]_{\mathrm{k} \chi}}\end{array}$ & *[FRIC & $\begin{array}{l}\text { IDENT-IO } \\
{[\text { cont }]_{\mathrm{V}}}\end{array}$ & *V-STOP & $\begin{array}{l}\text { IDENT-IO } \\
{[\text { cont }]}\end{array}$ \\
\hline a. levatscm \& livtsom $(0.8)$ & & & & & $*$ \\
\hline b. lebatsem \& libtsom (0.2) & & & & $*$ & \\
\hline
\end{tabular}

Recall that two sets are required to account for the alternation patterns encountered by [v] in the input as opposed to $[\mathrm{k}]$ and $[\chi]$. In (20), we see that the variable ranking of the set-indexed faithfulness constraint

\footnotetext{
${ }^{5}$ Note that, for simplicity, we use two contextual markedness constraints in the analysis of nonce verbs - $*$ V-Stop prohibits post-vocalic stops, and *[Fric prohibits word-initial fricatives.
} 
for [v] with the markedness constraint prohibiting word-initial fricatives allows for higher levels of acceptable non-alternation for $[\mathrm{v}]$ than the other labials.

(20) [v] in input: Preference for alternation at lower rate [bagal] / [bigel] $(73 \%) \sim$ [vagal] / [vigel] $(27 \%)$

\begin{tabular}{|l||l:l|l|l|l|}
\hline /livgol/ & $\begin{array}{l}\text { IDENT-IO } \\
{[\text { cont }]_{\mathrm{k} \chi}}\end{array}$ & $*[$ FRIC & $\begin{array}{l}\text { IDENT-IO } \\
{[\text { cont }]_{\mathrm{v}}}\end{array}$ & $*$ V-STOP & $\begin{array}{l}\text { IDENT-IO } \\
{[\text { cont }]}\end{array}$ \\
\hline \hline a. bagal \& bigel $(0.73)$ & & & $*$ & $*$ & $*$ \\
\hline b. vagal \& vigel $(0.27)$ & & $*$ & & $*$ & \\
\hline
\end{tabular}

Finally, in (21), we see the preference for non-alternation in the dorsals $[\chi]$ and $[\mathrm{k}]$. The higher frequency with which this set's indexed faithfulness constraint outranks the markedness constraints allows for a higher frequency of non-alternation in the output.

$$
[\chi i t \varepsilon z](72 \%) \sim[k i t \varepsilon z](28 \%)-\text { Preference for non-alternation }
$$

\begin{tabular}{|l||l:l:l|l:l|}
\hline$/$ le $\chi$ atez/ & $\begin{array}{l}\text { IDENT-IO } \\
{[\text { cont }]_{\mathrm{k}}}\end{array}$ & $*[$ FRIC & $\begin{array}{l}\text { IDENT-IO } \\
{[\text { cont }]_{\mathrm{V}}}\end{array}$ & $*$ V-STOP & $\begin{array}{l}\text { IDENT-IO } \\
{[\text { cont }]}\end{array}$ \\
\hline \hline a. $\chi$ itez $(0.72)$ & $*$ & & & $*$ & \\
\hline b. kitez $(0.28)$ & & $*$ & & $*$ & $*$ \\
\hline
\end{tabular}

\section{Conclusion}

In this paper, we detail a production experiment designed to elicit stop/fricative alternation in both real and nonce verbs in Modern Hebrew. This was a follow-up study to a perception experiment described in Temkin Martínez (2010). Results indicate that preference patterns in the production of real verbs followed those in the perception study. Patterns in nonce verbs illustrate a connection between preference for alternation and the number of graphemes used in the language to represent each stop/fricative pair. A modification to the combined model proposed in Temkin Martinez (2010), allowing set indexation assignment based on orthographic representation, was presented to account for the different preference patterns in the nonce verbs.

\section{References}

Adam, Galit. 2002. From Variable to Optimal Grammar: Evidence from Language Acquisition and Language Change. Ph.D. Dissertation. Tel-Aviv University.

Boersma, Paul. 1998. Functional Phonology: Formalizing the Interactions between Articulatory and Perceptual Drives The Hague: Holland Academic Graphics.

Boersma, Paul \& Bruce Hayes. 2001. Empirical Tests of the Gradual Learning Algorithm. Linguistic Inquiry 32.45-86. Bolozky, Shmuel. 1980. Paradigm Coherence: Evidence from Modern Hebrew. Afroasiatic Linguistics 7.103-26.

Hayes, Bruce \& Zsuzsa Londe. 2006. Stochastic Phonological Knowledge: The Case of Hungarian Vowel Harmony. Phonology 23.59-104.

Hayes, Bruce \& Margaret MacEachern. 1998. Quatrain Form in English Folk Verse. Language 74.473-507.

Hayes, Bruce, Bruce Tesar, and Kie Zuraw. 2013. "OTSoft 2.3.2," software package, http://www.linguistics.ucla.edu/people/hayes/otsoft/.

Pater, Joe. 2000. Non-uniformity in English Stress: The Role of Ranked and Lexically Specific Constraints. Phonology 12.237-74.

Schwarzwald, Ora. 1981. Grammar and Reality in the Hebrew Verb. Bar-Ilan University Press, Israel.

Temkin Martínez, Michal. 2008. Exceptionality and Variation in Modern Hebrew. In Natasha Abner \& Jason Bishop (eds.) West Coast Conference on Formal Linguistics (WCCFL) 27. Somervillle, MA: Cascadilla Proceedings Project.

Temkin Martínez, Michal. 2010. Sources of Non-conformity in Phonology: Variation and Exceptionality in Modern Hebrew Spirantization. Ph.D. Dissertation. University of Southern California.

Temkin Martinez, Michal. 2012. Modeling Acceptability of Variation in Modern Hebrew. In Stefan Huber \& Sonia Ramirez Wohlmuth (eds.) Tampa Papers in Linguistics (TPL) 3. 89-100.

Zuraw, Kie. 2000. Patterned Exceptions in Phonology Ph.D. Dissertation. UCLA. 